\title{
Slotted Circular Microstrip Patch Antenna Designs for multiband Application in Wireless Communication
}

\author{
Hemant Kumar Gupta, P.K.Singhal,Pavan Kumar Sharma,Veerendra Singh \\ Jadon \\ Department of Electronics, Madhav Institute of Technology \&Science Gwalior \\ (M.P) 474005-India \\ Email: \\ hmnt_gpt@yahoo.co.in,pks_65@yahoo.com,Sharmapavan.0511@gmail.com,veer \\ mtech@gmail.com
}

\begin{abstract}
The paper present the Circular Microstrip Patch Antenna designs with slit-slot for multiband purpose in wireless communication. We have designed a circular microstrip patch antenna (CMPA) for $1.3 \mathrm{GHz}$ used in wireless communication. We have designed CMPA with 2slit slot, 3slit-slot, and 6slit-slot and observed results for different designs, and finally it is shown that as slit-slot increases to six slit-slots bandwidth is initially increased up to 3 slit-slots and finally reduced for six slitslots. The multiband antenna uses for wireless communication in different applications. Bandwidth improvement is about $63.3 \%$, $72.10 \%$ and $37.5 \%$ respectively in two, three and six slit-slotted patch when compared to their basic design bandwidth band. Antenna is changed to multiband by slit-slot Circular Microstrip Patch Antenna (CMPA).
\end{abstract}

Keywords: Circular Microstrip Patch Antenna (CMPA), CST (Computer Simulation Technology).

\section{Introduction}

Circular Microstrip Patch Antenna is very useful because of its small-size, ease of fabrication. 
Sirpenski design for $2.45 \mathrm{GHz}$ is presented in this paper found very efficient because the antenna efficiency is very high about $82 \%$.sirpenski design has numerous advantage like having a lesser return loss and lesser size of antenna [1].

Antenna for efficient rectenna is presented on this paper at ISM band.DGS structure are also used in this paper, because of the DGS design antenna do not shows any Harmonics at particular band [2].

Circularly polarized microstrip antenna is proposed in this paper which also found efficient for rectenna design. Antenna radiation pattern is also independent of the radiation pattern of antenna [3]

A new design technique of microstrip patch antenna is presented in this paper. The proposed antenna design consists of inverted patch structure with air-filled dielectric, direct coaxial probe feed technique and the novel slotted shaped patch. The maximum achievable gain is $9.41 \mathrm{dBi}$. The achievable experimental 3-dB beam width (HPBW) in the azimuth and elevation are 60.88 \pm and $39 \pm$ respectively at centre frequency [4].

The enhancing bandwidth and size reduction mechanism that improves the performance of a conventional microstrip patch antenna on a relatively thin substrate (about0.01 0 $\lambda$ ) is presented in this research. The design adopts contemporary techniques; L-probe feeding, inverted patch structure with air-filled dielectric, and slotted patch [5].

In this study, the design and analysis of a (2x2) microstrip patch antenna array is introduced. It is designed to function in the $5.25 \mathrm{GHz}$ which corresponds to IEEE 802.11a (VSWR<2, data rate 54Mbps/ B.W $20 \mathrm{~dB}$ and S-parameters, Sij <-20dB where $\mathrm{i} \neq \mathrm{j}$ ) wireless LAN application [6]

\section{Antenna Design}

Different Slit-Slotted Circular Microstrip Patch Antenna (CMPA) Designs shown in this paper for multiband applications.

The height and dielectric constant of the substrate chosen according to the design frequency of the antenna. The design frequency used here is a $1.3 \mathrm{GHz}$ for the designs. Substrate parameter is given as:-

Dielectric constant of the substrate $=4.3$

Height of the substrate $=1.6$

Loss tangent of the substrate $=.02$ 


\subsection{Circular Microstrip Patch Antenna Design}

First we design a circular microstrip patch antenna for at $1.3 \mathrm{GHz}$.all design parameters are calculated by a reference book of antenna design [7]. All parameter related to the design of antenna given in the table below:-

Table: 1 Circular Patch Parameter

\begin{tabular}{ccccc}
\hline $\begin{array}{c}\text { Radius of circular } \\
\text { patch }\end{array}$ & $\begin{array}{c}\text { Cut } \\
\text { width }\end{array}$ & $\begin{array}{c}\text { Cut } \\
\text { depth }\end{array}$ & $\begin{array}{c}\text { Continue path } \\
\text { length }\end{array}$ & $\begin{array}{c}\text { Continue path } \\
\text { width }\end{array}$ \\
\hline $32.61 \mathrm{~mm}$ & $16.50 \mathrm{~mm}$ & $20 \mathrm{~mm}$ & $53.95 \mathrm{~mm}$ & $2.32 \mathrm{~mm}$ \\
\hline
\end{tabular}

Although only radius of patch is calculated by a reference book and all the calculation find out by iteration on CST-MWS software and find out the data for a best results all the graphs or figures related to design of patch given below:-

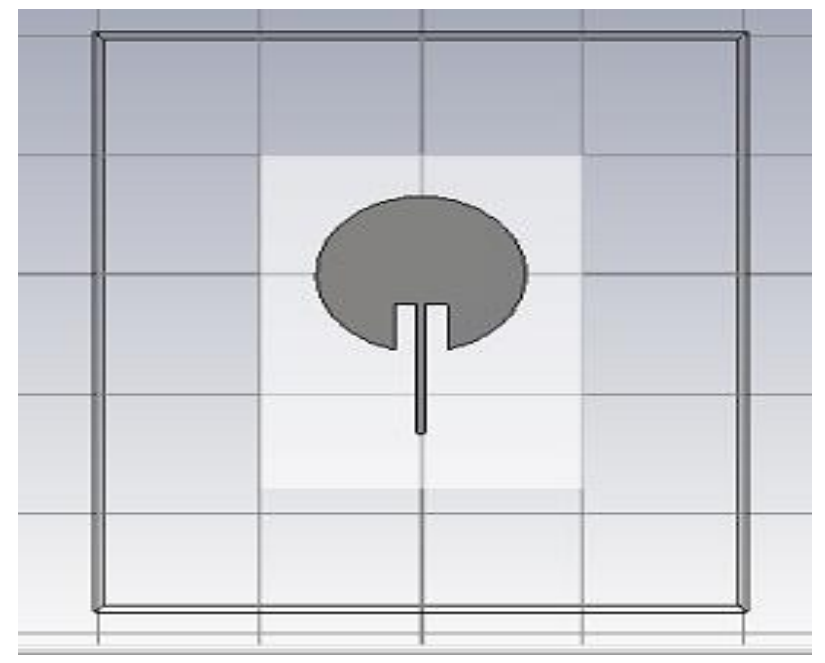

Fig. 1 Circular microstrip patch 


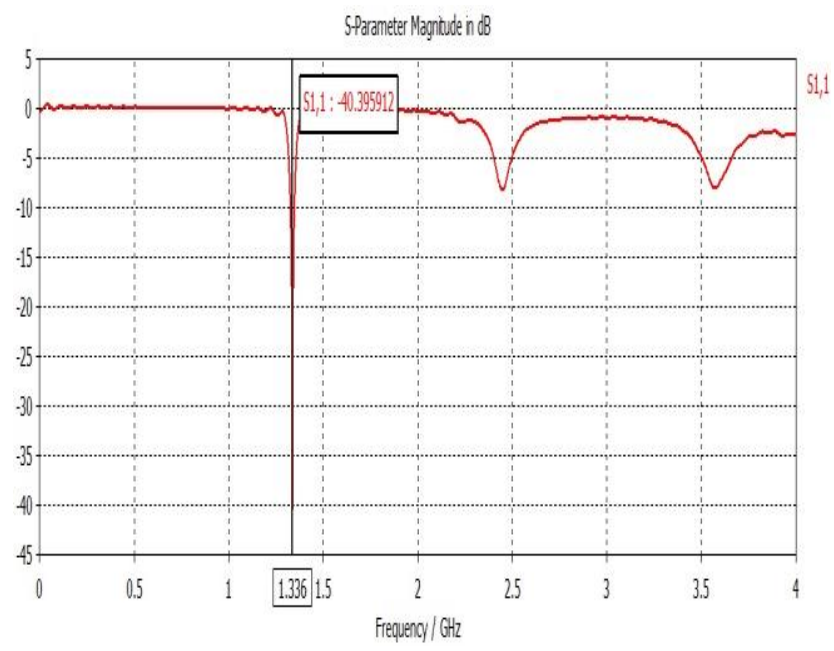

Fig, 2 Return losses vs. frequency for circular patch without slot

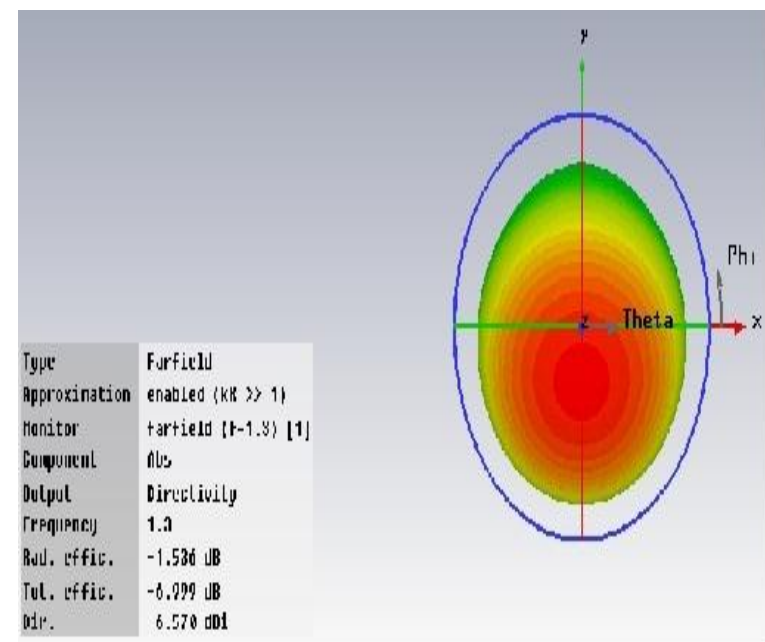

Fig. 3 Radiation pattern of simple circular patch at $1.3 \mathrm{GHz}$

Practical Design of Circular Microstrip patch AS shown in fig. below:- 


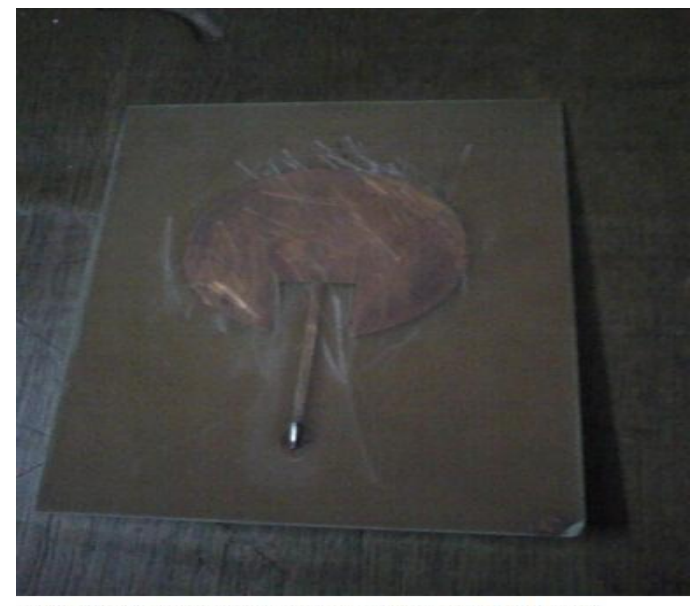

Fig.4 Circular Microstrip Patch Antenna Design at $1.3 \mathrm{GHz}$

\subsection{Circular Microstrip Patch Anteena with 2 Slit-Slot}

Circular microstrip patch antenna with 2 slit-slot is also design by CST-MWS software at $1.3 \mathrm{GHz}$ and Simulation results of return loss and radiation pattern by CST-MWS software are shown in the figure below:-

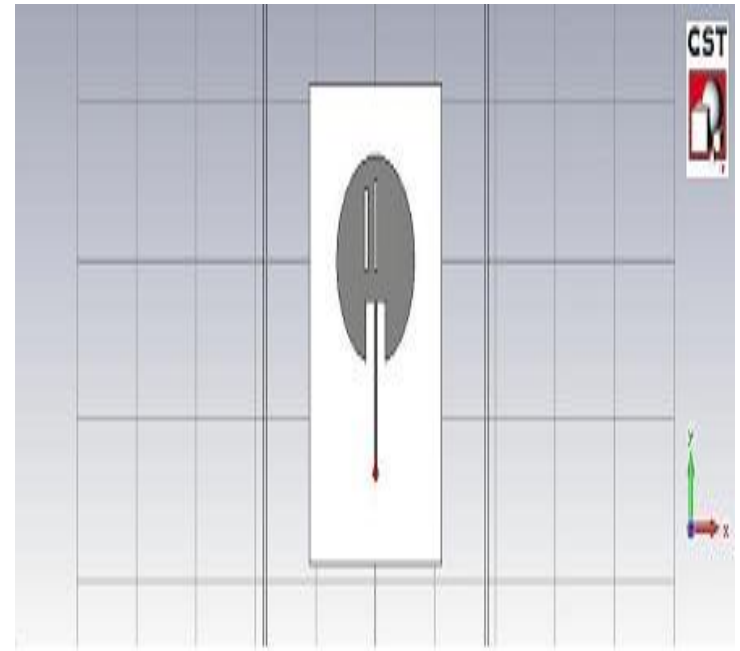

Fig.5 CMPA With 2slit-slot for Multiband Application 


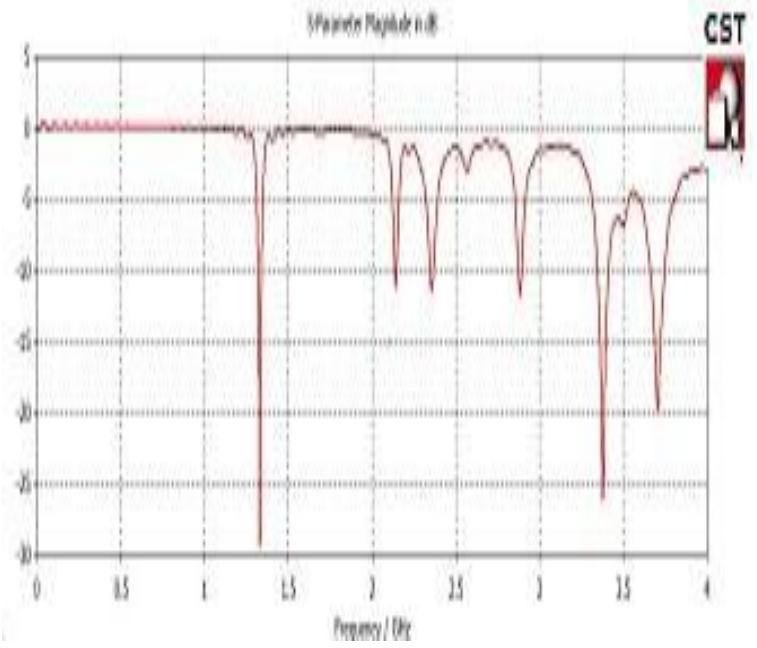

Fig. 6 Radiation pattern of CMPA with 2 slit slot- structure

Table 2: Two slit-slots Band of Circular Microstrip Patch Parameter

\begin{tabular}{cccc}
\hline S.NO & Frequency $(\mathrm{GHz})$ & Return loss $(\mathrm{dB})$ & Bandwidth $(\mathrm{MHz})$ \\
\hline 1 & 1.328 & 29.312 & 23.2 \\
2 & 2.142 & 11.065 & 12.1 \\
3 & 2.3529 & 11.205 & 24.4 \\
4 & 2.88 & 11.78 & 20.3 \\
5 & 3.3793 & 24.97 & 60.8 \\
6 & 3.7039 & 19.88 & 63.3 \\
\hline
\end{tabular}

It is very clear from the table 2 that antenna with two slit become multiband antenna in $0-4 \mathrm{GHz}$ Span and bandwidth is increased approximately $63.3 \%$ as compared to Bandwidth for Designed Frequency and antenna become useful for multiband purposes

\subsection{Circular Microstrip Patch Antenna Design for 3 Slit-Slots}

Design Antenna and its Return loss Charactestric is find out by a CST-MWS Software shown below 


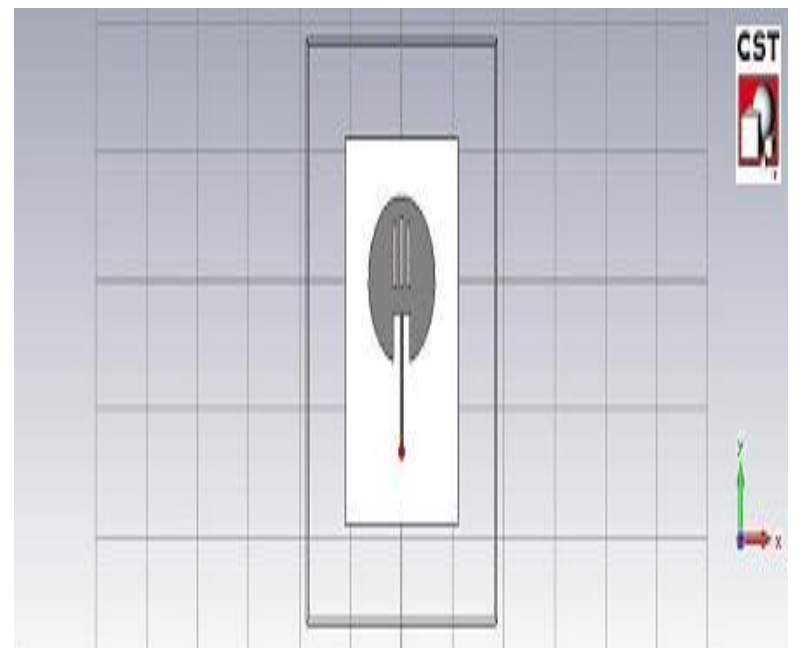

Fig.7. CMPA With 3Slit-slot for Multiband Application

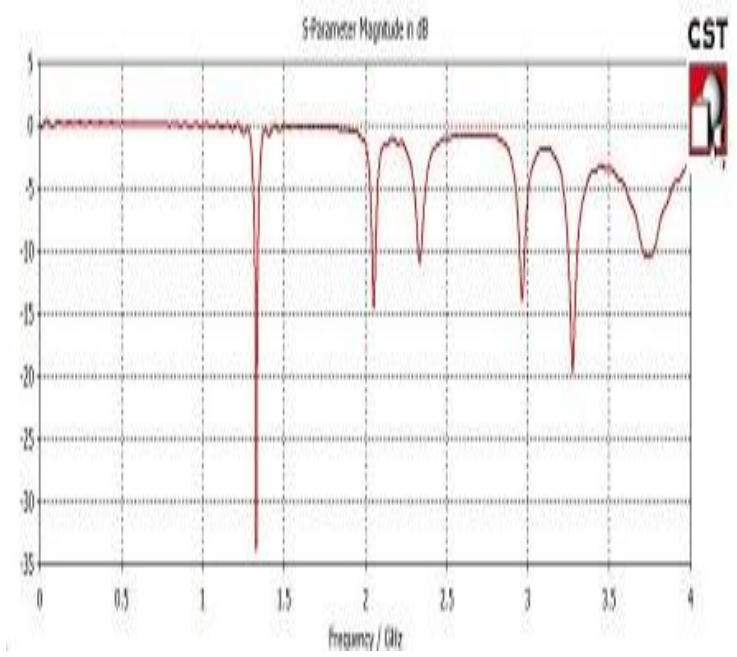

Fig.8 Radiation pattern of CMPA with 3 slit slot- structure

Table 3:Three Slit-Slot Band of Circular Microstrip Patch Parameter

\begin{tabular}{cccc}
\hline S.NO & Frequency $(\mathrm{GHz})$ & Return loss $(\mathrm{dB})$ & Bandwidth(MHz) \\
\hline 1 & 1.328 & 33.822 & 24.3 \\
2 & 2.05 & 14.60 & 23 \\
3 & 2.3408 & 10.765 & 24.4 \\
4 & 2.9665 & 13.87 & 40.6 \\
5 & 3.2779 & 19.31 & 51.1 \\
6 & 3.7444 & 10.54 & 87.1 \\
\hline
\end{tabular}

As it is Very clear from the Table three Data that Maximum B.W is achieved 87.1MHZ so improvement in Bandwidth is about $72.10 \%$ this is a tremendous 
improvement in bandwidth of antenna. Antenna is working on 6 different frequencies and it is proving multiband charactestric property of antenna

\subsection{Circular Microstrip Patch Antenna Design for 6-Slit-Slots}

Design Antenna and its Return loss Charactestric is find out by a CST-MWS Software shown below:-

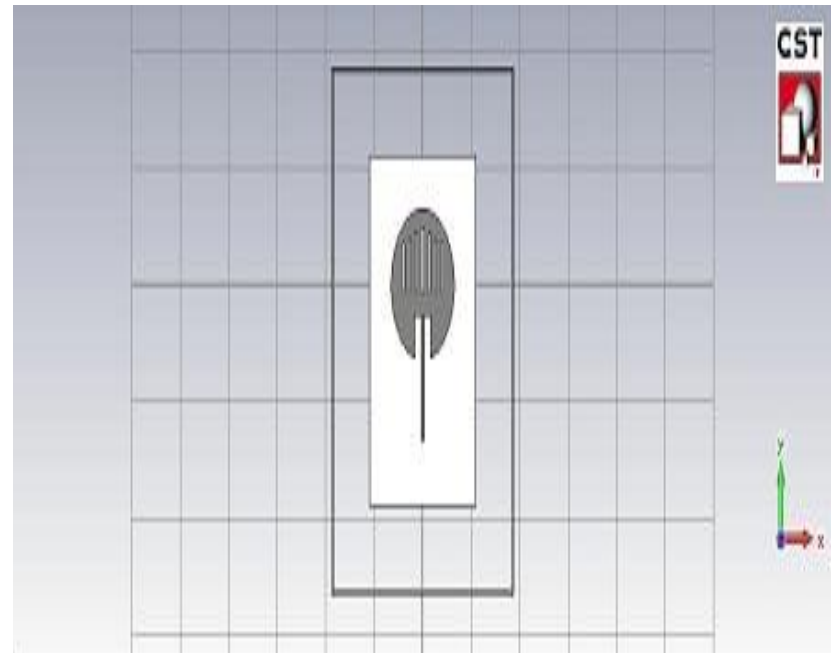

Fig.9. CMPA With 6 Slit-slot for Multiband Application

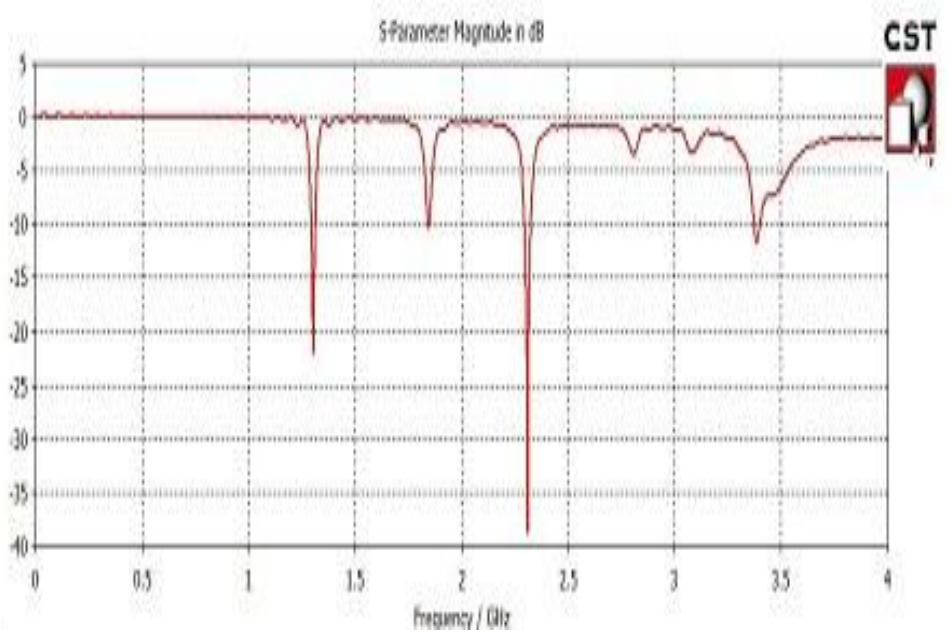

Fig. 10 Radiation pattern of CMPA with 6 slit slot- structure 
Table 4: Six Slit-Slot parameter of Circular Microstrip Patch Antenna

\begin{tabular}{cccc}
\hline S.NO & Frequency $(\mathrm{GHz})$ & Return loss $(\mathrm{dB})$ & Bandwidth $(\mathrm{MHz})$ \\
\hline 1 & 1.304 & 21.996 & 20.3 \\
2 & 1.8458 & 10.020 & 17.3 \\
3 & 2.312 & 38.58 & 28.4 \\
4 & 3.388 & 11.62 & 32.5 \\
\hline
\end{tabular}

As it is very clear from the Table- 4 that 6 peaks reduces to 4 peaks and retrunloss and bandwidth is also reduced, although Bandwidth improvement from designed frequency is only about $37.5 \%$.

\section{Discussion}

As we can easily see in Table 2, 3 and 4 and compared it from Table-1 that Bandwidth is increased by two slit slot patch is about $63.3 \%$ as compared to its basic design frequency. Antenna is working for six different frequencies may be used for multiband in different wireless communication. Antenna with 3-slit slot is also working fine for different six frequencies bandwidth is increased about $72.10 \%$ as compared to its basic designed frequency bandwidth. Antenna with six slit-slots is also designed and it is working only for 4-band instead of 6, Bandwidth is increased about $37.5 \%$ compared to its basic designed frequency bandwidth. There is less improvement in six-slot patch as compared to two and three slit-slot patches.

\section{Results}

Finally it is shown from the above discussion that as we increases slit-slot from one to three bandwidth and multiband charactestric introduced, but as slit-slot increases to six working band are reduced and bandwidth is also reduced to compare from two and three slit-slot. There is drastic improvement in bandwidth by slit-slot patches compared with it designed frequency peak about 1.3GHz.There is improvement in bandwidth about $63.3 \%, 72.10 \%$ and $37.5 \%$ respectively in two, three and six slit-slot patches compared to their basic design frequencies band which is about $1.3 \mathrm{GHz}$.

\section{References}

[1] Pavan Kumar Sharma,Hemant Kumar Gupta,Ritesh Kumar Tambulker Veerendra Singh Jadon "Design of Sierpinski Microstrip Patch Antenna for Wireless Power Transmission for ISM Band (2.45GHz)" on International Conference at SRGI Jhansi Proceedings name "E-Manthan". 
[2] Zied Harouni, Lotfi Osman, Ali Gharsallah, "Efficient 2.45Ghz Rectenna Design with High Harmonics Rejection for Wireless Power Transmission" in IJCSI, vol. 7, Issue 5,pp.418-423, September 2010.

[3] Y.-Y Gao,X.-X. Yang, and J.-Y.Zhou, "A Circularly Polarized Rectenna With Low Profile for Wireless Power Transmission" in PIER, vol. 13., pp. 41-49, 2010.

[4] M.T.Islam,M.N.Shakib,N Misran "Multi-Slotted Microstrip Patch Antenna For Wireless Communication"in Pier Vol-10,pp11-18 2009.

[5] Mohammad Tariqul Islam, Mohammed Nazmus Shakib,Norbahiah Misran, Tiang Sew Sun "Broadband Microstrip Patch Antenna"in European Journal of Scientific Research Vol.27 No.2 (2009), pp.174-180.

[6] Chandan Kumar Ghosh, Susanta Kumar Parui Design, Analysis and Optimization of A Slotted Microstrip Patch Antenna Array at Frequency 5.25 GHz for WLAN-SDMA System in IJEEI Volume 2, Number 2, 2010.

[7] C. Balinies, "Antenna Theory", Wiley, 2nd addition chapter -14 ISBN 0-47159268-4., (1997).

[8] http://www.cst.com/content/products/mws/overview.aspx C) 2012 CST Computer Simulation Technology AG. 